\title{
Ferramentas de participação e transparência em websites de prefeituras brasileiras ${ }^{1}$
}

PARTICIPATION AND TRANSPARENCY TOOLS

IN WEBSITES OF BRAZILIAN MUNICIPALITIES

\section{Othon Jambeiro}

Docente-pesquisador do Programa de Pós-Graduação em Comunicação e Cultura

Contemporâneas, Faculdade de Comunicação, Universidade Federal da Bahia.

E-mail: othonfernando@gmail.com

\section{Maristela Oliveira}

Professora Adjunta do Departamento de Estatística, no Instituto de Matemática e Estatística da Universidade Federal da Bahia.

E-mail: marridias@gmail.com

\section{Vanice da Mata}

Mestranda no Programa de Pós-Graduação em Comunicação e Cultura Contemporâneas; Bolsista AT-NS/CNPq no Instituto Nacional de Ciência e Tecnologia em Democracia Digital (INCT-DD). E-mail: vanicedamata@gmail.com

\section{Recebido em $1^{\circ}$ de março de 2018. Aprovado em 13 de abril de 2018.}

\section{Resumo}

$\mathrm{O}$ artigo traz um retrato do uso de ferramentas de participação social e transparência da gestão nos websites de municípios brasileiros. Os dados foram cruzados com a variável Taxa de Urbanização (TU). Os procedimentos metodológicos abrangeram: (i) levantamento dos websites das prefeituras de municípios com mais de 20 mil habitantes; (ii) construção de plano amostral; e (iii) análise de 291 websites constantes da amostra. Foi aferida baixa correlação entre TU e o uso dessas ferramentas.

Palavras-chave: Websites municipais. Participação social. Transparência de gestão.

1 A pesquisa em que se baseia este artigo foi realizada com recursos do CNPq. 


\section{Abstract}

The article traces a portrait of the use of social participation and transparency tools in websites of Brazilian municipalities. Data were crossed with the variable Urbanization Rate (TU). Methodological procedures consisted of: (i) identify websites of municipalities with more than
20.000 inhabitants; (ii) construct a sample plan; and (iii) analyze websites of the 291 municipalities included in the sample. A low correlation was found between TU and the use of these tools.

Keywords: Municipal websites. Social participation. Public administration transparency.

\section{Introdução}

O uso crescente das tecnologias de informação e comunicação (TIC) dificulta que o poder público municipal negue aos cidadãos a elevação de seus níveis tanto de informação, quanto de participação nos processos decisórios da municipalidade. Elas estão todo o tempo sendo usadas cada vez por maior número de pessoas, para interações de variada natureza; e se ocorrem tão intensamente na vida social, por que não deveriam ocorrer também na vida política?

É neste cenário que o poder público municipal tem que responder à demanda dos cidadãos por mais e por melhores canais de participação e de informação sobre o que e porque são realizadas as ações e os projetos da municipalidade. Demandas que são interligadas e para as quais é, hoje, essencial a utilização de tecnologias avançadas de informação e comunicação. Fragmentos de um mundo em rede digital, as instâncias de gestão se veem pressionadas a estar também nesta rede e nela inserir, por meio de ferramentas apropriadas, seus cidadãos e a si próprias. E não só: as pressões ocorrem também no sentido de modernização, de eficiência na aplicação de recursos, de transparência no trato das questões de natureza pública. O impulso - que se torna mais forte porque vem crescentemente por meio da rede digital - repete-se, alastra-se e se consolida. Isto é, ao invés de ser exceção, torna-se regra, comportamento e curso normal.

Este texto analisa a presença, nos websites de prefeituras brasileiras, de ferramentas para a transparência de gestão e para a participação dos cidadãos, e a relação desta presença com a Taxa de Urbanização (TU) do município. A análise faz parte de uma pesquisa mais ampla, destinada a investigar as políticas relativas à adoção e uso das TIC em municípios brasileiros, a partir de seus websites e planos diretores².

2 Os resultados completos da pesquisa serão publicados em livro, ainda em 2018, com o título: Tecnologias de Informação e Comunicação na Gestão dos Municípios Brasileiros-Participação, Eficiência e Transparência. 
A pesquisa teve como universo os 1.758 municípios brasileiros com mais de 20 mil habitantes ${ }^{3}$, de acordo com planilha publicada pelo IBGE em julho de 2016 (IBGE, 2016). Excluídos o distrito federal e as capitais ${ }^{4}$, são 1.733 os municípios que compõem a população alvo $^{5}$ da pesquisa. Esses municípios foram objeto de um levantamento preliminar, visando verificar a existência de websites das prefeituras. Os resultados obtidos foram lançados em planilha Excel, complementada com dados de qualificação dos municípios ${ }^{6}$. Um plano amostral indicou 291 municípios como representantes do universo pesquisado.

Uma vez que as concentrações urbanas tendem a favorecer e estimular uma cultura de uso intenso de tecnologias avançadas de informação e comunicação (WHEELER; AOYAMA; WARF, 2000; CASTELLS, 2002), infere-se que a TU está diretamente relacionada com a adoção e uso das TIC, e esta relação deveria estar evidente nos websites municipais. Utilizou-se como parâmetro a TU nacional $(84,36 \%)$ - a mais recente publicada pelo IBGE com base no Censo de 2010 (IBGE, 2010). Foram estabelecidas quatro faixas de classificação de TU dos municípios analisados: Baixa=menos de $65 \%$; Média $=$ de $65 \%$ a 74,99\%; Alta=de 75\% a 84,99\%; Muito Alta=a partir de $85 \%$.

A análise e interpretação dos dados foram concluídas em novembro de 2017. A seleção da amostra, o cruzamento das variáveis, a geração das tabelas e gráficos e o cálculo das correlações foram realizados com o auxílio do software estatístico $\mathrm{R}^{7}$.

\section{As prefeituras e o dever de informar}

O uso das TIC tem ajudado o poder público municipal a governar por meio do chamado e-gov, no qual os cidadãos podem ter acesso a serviços oferecidos pela prefeitura, assim como podem elevar seus níveis de participação social e política (BERG; WINDEN, 2002, p. 265). Os mesmos autores sugerem, ainda, que a internet pode melhorar a qualidade de vida nos municípios utilizando-se, por exemplo, de serviços como

3 A Constituição Federal (Capítulo II, da Política Urbana) determina que municípios com mais de 20 mil habitantes devem elaborar um plano diretor de desenvolvimento. Este mesmo universo foi adotado para análise dos websites.

4 O Distrito Federal e as capitais dos estados foram excluídos por serem atípicos em relação à quase totalidade dos municípios existentes no país.

5 População alvo ou população objetivo é definida como a população que se pretende atingir com a pesquisa (BOLFARINE; BUSSAB, 2005, p. 7).

6 Todo o levantamento inicial foi feito pela P\&A - Pesquisa e Análise Social e Econômica, empresa especializada com sede em Salvador. Os autores são gratos a esta empresa pela dedicação e seriedade com que realizou o trabalho.

7 O R é um software de domínio público com diversas ferramentas estatísticas e possui atualização contínua. É distribuído gratuitamente por The R Foundation for Statistical Computing, a partir do endereço $<$ https:// cran.r-project.org/>. Neste trabalho, foi utilizada a versão 2.9.2. 
teleconsulta para quem necessita de assistência médica, ou divulgando eventos culturais e permitindo reservas on-line.

Há, de fato, um grande número de informações relacionadas ao cotidiano dos indivíduos que, se disponíveis via internet, podem facilitar a interação entre o cidadão e o governo municipal: horários de ônibus urbanos e interurbanos, disponibilidade de vagas em escolas públicas, agendamento de consultas médicas, formulários para recolhimento de impostos etc. Ressalte-se que, a despeito dessas informações disponíveis na web facilitarem o exercício de alguns atributos da cidadania, isto não é garantia de participação plena do indivíduo.

Incluído como prioridade na pauta de entidades que lidam com o tema, o direito à informação significa não só o acesso, mas também a possibilidade de o cidadão se capacitar para o exercício da liberdade de expressão, a fim de que possa tornar efetivamente públicas suas ideias e opiniões. Para tanto, é necessária a formulação de políticas e estratégias mais amplas e democráticas de adoção e uso universal das tecnologias avançadas de informação e comunicação.

Foi dentro deste contexto que, desde o final da década de 1990, o uso da internet passou a ser requerido dos governos como ferramenta de transparência de seus atos. A partir de então, informações e serviços públicos têm crescentemente migrado para o meio virtual. A visibilidade e a operacionalização disto acontecem por meio dos chamados portais, através dos quais os governos procuram se aproximar dos cidadãos e serem por eles percebidos. Essas interfaces são, pois, pelo menos em tese, locais de interação entre governantes e cidadãos, criando, em tese, um ambiente coletivo de diálogo e decisão. Em consequência, ao estimular maior interação e transparência entre sociedade e governo, as gestões ampliam o espaço para o exercício da cidadania e da prática democrática.

Isto beneficia também os governos, como resposta às pressões para que busquem eficiência e transparência por meio da incorporação de representações da sociedade civil em seus processos decisórios (TEIXEIRA, 2004, p. 14). Argumenta-se que se a população participa desses processos, a consequência esperada é que a gestão seja mais eficiente, o que, além de proporcionar economia de custos e aumento de eficácia administrativa e operacional, facilita e estimula a transparência de gestão. Além disso, quando um governo expõe suas ações e presta contas, submete-se à avaliação da população e se distancia de uma forma autoritária de governo. O diálogo constante e direto com a população permite-lhe detectar falhas da gestão e corrigi-las, assim como obter resposta rápida sobre aceitação ou recusa de novos programas e projetos.

Argumenta-se também que a transparência nas decisões confere ao governo maior credibilidade e inibe a corrupção, pois "quanto maior for a quantidade de informação disponível abertamente pelo governo e sobre o governo, menor será a possibilidade de se 
conseguir ocultar atos ilegais, corrupção e má administração" (UHLIR, 2006, p. 37). A transparência, portanto, estimula a democratização, dando a todos a possibilidade de conhecer, criticar e opinar sobre as ações do governo, otimizando-o e evitando que seja autoritário.

\section{Governo, internet e marcos legais}

A condição primordial para uma gestão democrática é que informações relevantes que envolvem o governo possam ser acessadas facilmente e de forma compreensível pelos cidadãos. A Constituição de 1988, no artigo 216, § $2^{\circ}$, assegura ao cidadão o direito de acesso a essas informações e designa a administração pública como responsável por garantir esse acesso: "cabem à administração pública, na forma da lei, a gestão da documentação governamental e as providências para franquear sua consulta a quantos dela necessitem" (BRASIL, 1988). Também o art. 5, Inciso XXXIII, estabelece que "todos têm direito a receber dos órgãos públicos informações de seu interesse particular, ou de interesse coletivo ou geral, [...], ressalvadas aquelas cujo sigilo seja imprescindível à segurança da sociedade e do Estado" (Ibid.).

A Constituição chega a ser repetitiva quanto a isto quando afirma:

Art. 37. A administração pública direta e indireta de qualquer dos Poderes da União, dos Estados, do Distrito Federal e dos Municípios obedecerá aos princípios de legalidade, impessoalidade, moralidade, publicidade e eficiência e, também, ao seguinte:

$\S 3^{\circ} \mathrm{A}$ lei disciplinará as formas de participação do usuário na administração pública direta e indireta, regulando especialmente:

I - as reclamações relativas à prestação dos serviços públicos em geral, asseguradas a manutenção de serviços de atendimento ao usuário e a avaliação periódica, externa e interna, da qualidade dos serviços;

II - o acesso dos usuários a registros administrativos e a informações sobre atos de governo, observado o disposto no art. $5^{\circ}$, X e XXXIII. (Ibid.)

Não bastasse isso, a Lei Complementar n. 101, de 4 de maio de 2000 (Lei de Responsabilidade Fiscal), determina, em seu Art. 48:

São instrumentos de transparência da gestão fiscal, aos quais será dada ampla divulgação, inclusive em meios eletrônicos de acesso público: os planos, orçamentos e leis de diretrizes orçamentárias; as prestações de contas e o respectivo parecer prévio; o Relatório Resumido da Execução Orçamentária e o Relatório de Gestão Fiscal; e as versões simplificadas desses documentos. (Id., 2000) 
Este artigo foi posteriormente alterado pela Lei Complementar n. 131, de 27 de maio de 2009, que acrescentou a ele o seguinte:

Parágrafo único. A transparência será assegurada também mediante

I - incentivo à participação popular e realização de audiências públicas, durante os processos de elaboração e discussão dos planos, lei de diretrizes orçamentárias e orçamentos;

II - liberação ao pleno conhecimento e acompanhamento da sociedade, em tempo real, de informações pormenorizadas sobre a execução orçamentária e financeira, em meios eletrônicos de acesso público. (Id., 2009)

Regulando o Art. 216 da Constituição, o Congresso Nacional aprovou a Lei n. 12.527, de 18 de novembro de 2011 (Lei do Acesso à Informação). Ela reafirma o direito fundamental de acesso à informação, os princípios constitucionais da administração pública e o dever do Estado de garantir esse direito, "mediante procedimentos objetivos e ágeis, de forma transparente, clara e em linguagem de fácil compreensão" (Id., 2011). E fixa como diretrizes:

I - observância da publicidade como preceito geral e do sigilo como exceção;

II - divulgação de informações de interesse público, independentemente de solicitações;

III - utilização de meios de comunicação viabilizados pela tecnologia da informação;

IV - fomento ao desenvolvimento da cultura de transparência na administração pública;

V- desenvolvimento do controle social da administração pública. (Ibid.)

No parágrafo $2^{\circ}$ do seu Art. $8^{\circ}$, remarcando a obrigatoriedade de os municípios terem websites próprios, a Lei diz que "deverão utilizar todos os meios e instrumentos legítimos de que dispuserem, sendo obrigatória a divulgação em sítios oficiais da rede mundial de computadores (internet)" (Ibid.). E vai mais além, determinando: (i) o modo como os websites devem disponibilizar as informações; (ii) que indiquem "local e instruções que permitam ao interessado comunicar-se, por via eletrônica ou telefônica, com o órgão ou entidade detentora do sítio"; e (iii) que tenham "a alternativa de encaminhamento de pedidos de acesso por meio de seus sítios oficiais na internet" (Ibid.).

Os governos municipais, por conseguinte, devem: publicar informações e promover o fácil acesso a elas; buscar convencer os cidadãos da importância de ter conhecimento das suas ações, que devem estar de acordo com as necessidades e aspirações da população; ouvir e levar em consideração as insatisfações e críticas; submeter-se à avaliação constante, a fim de verificar o nível de satisfação dos cidadãos em relação à gestão. 
Sorj (2003, p. 88) afirma que o uso da internet contribui para a democratização do Estado, destacando-se entre seus benefícios a "redução da corrupção, da apropriação privada dos bens públicos e o enorme desperdício e ineficiência aos quais o estado e o funcionalismo público estiveram associados". De fato, a transparência e a eficiência da gestão pública vêm se beneficiando nos últimos anos da crescente aplicação das TIC, por vários segmentos de governo. É significativa a presença na web de informações sobre ações de governo, prestação de contas de gastos e investimentos, oferta de serviços on-line, dentre outras aplicações.

Em suma, só é possível participar daquilo que se conhece. O cidadão que ignora ações e informações governamentais não tem instrumentos para interferir na gestão pública, ainda que lhe seja dada a oportunidade. O governo que não promove o acesso nem põe em debate público suas ações e informações está dificultando o exercício da democracia. Uhlir (2006, p. 37) afirma que "a maximização do fluxo aberto e irrestrito de informação entre o governo e o público é um aspecto fundamental para uma sociedade democrática e para a promoção de uma boa governança”. Pode-se mesmo afirmar que o nível de democratização é proporcional ao nível de transparência do governo.

\section{Participação e controle social, por taxa de urbanização}

A questão básica que se buscou responder foi: as prefeituras usam seus websites na internet para conquistar eficiência e transparência da gestão e para incrementar o exercício da cidadania? Para isto verificou-se nos websites a existência de ferramentas tanto para disponibilização de informação aos cidadãos, quanto para sua participação cívica. Inexistindo um website da prefeitura, os blogs e perfis no Facebook foram considerados isoladamente, cada um pontuando exclusivamente nas ferramentas que disponibilizavam.

Somente ouvidorias das prefeituras foram computadas, desconsiderando aquelas cujos links levaram a ouvidorias de secretarias (usualmente a da saúde) ou a ouvidorias gerais de estado. No item e-mails e/ou telefones executivos, pontuaram municípios cujos contatos válidos de secretários e prefeitos representaram $50 \%$ ou mais deste universo. Se um município apresentou links diferentes para contato com prefeito e secretários, mas que levaram a um único número de telefone e a um mesmo e-mail, o website da prefeitura foi pontuado com zero nesse item.

Em termos de conteúdo do website foram buscadas ferramentas agrupadas em duas categorias: 
A. Participação cívica on-line (PCO), explicitada pelas ferramentas: (i) Fale Conosco; (ii) Canais On-line (Facebook, Twitter, YouTube, Instagram, dentre outros); (iii) Ouvidoria; (iv) e-mails e/ou telefones do gabinete do prefeito e das secretarias executivas municipais;

B. Controle social da gestão (CSG), explicitado pelas ferramentas: (i) Agenda do Prefeito; (ii) Plano Diretor do Município; (iii) Acesso à Informação via Portal da Transparência ou via e-SIC; (iv) Ferramenta de Busca.

Tanto no conjunto A como no B não houve teste de eficácia das ferramentas nem dos conteúdos das informações; apenas verificou-se sua existência.

Os dois conjuntos foram valorados da seguinte forma:

A. Cada um deles vale até 4 pontos, uma vez que as ferramentas neles contidas valem 1 ponto. Para o item e-mails e/ou telefones executivos foi atribuído 0,5 ponto para informações dos prefeitos e 0,5 ponto para informações das secretarias executivas municipais. Isto foi feito porque se considerou que disponibilizar apenas meios de acesso exclusivamente ao prefeito e não aos seus secretários, ou vice-versa, não se constituía em acesso pleno à gestão.

B. No caso do item canais de acesso à informação foi atribuído 0,5 ponto ao Portal da Transparência e 0,5 ponto ao e-SIC. Neste caso considerou-se que a transparência de informações só se completa quando coexistem o acesso passivo (o portal) e o ativo (o e-SIC): no primeiro, verifica-se a disponibilização das informações previstas em lei, e no segundo, se está assegurado ao cidadão o direito de solicitar outras informações que julgar de seu interesse, o que é também previsto em lei.

C. Este sistema de valoração permitiu analisar separadamente cada ferramenta, cada conjunto (PCO e CSG), o website/município como um todo (PCO+CSG somados), além da correlação desses elementos com a TU.

D. Nas tabelas, "Pontos" é a frequência de websites das prefeituras que disponibilizam cada uma ou o conjunto de ferramentas. Os percentuais estão estabelecidos pela relação entre os pontos conseguidos e o número de municípios da região ou toda a amostra quando se trata da coluna Total.

Os 291 municípios estão distribuídos pelas regiões brasileiras da seguinte forma: 32 na Região Norte; 92 na Região Nordeste; 99 na Região Sudeste; 48 na Região Sul; e 20 na Região Centro-Oeste. 


\section{Brasil}

Verifica-se na Tabela 1 que, no caso de PCO, a ferramenta Fale Conosco apresenta a maior frequência em todas as faixas de TU. Curiosamente, está mais presente nos websites dos municípios classificados nas faixas extremas: a Baixa e a Muito Alta, embora os percentuais das faixas intermediárias, Média e Alta, não estejam muito distantes. Entretanto, no país como um todo, esta ferramenta alcança frequência de $87,3 \%$, distante aproximadamente $23,0 \%$ da segunda colocada - e-mails e/ou telefones executivos, com $64,8 \%$. Houve um empate na terceira posição entre Canais On-line $(53,6 \%)$ e Ouvidoria $(53,3 \%)$.

Tabela 1. Número de pontos conseguidos pelos websites quanto aos conjuntos de ferramentas PCO e CSG, pelas faixas de Taxa de Urbanização (TU) - Brasil, 2017

\begin{tabular}{|c|c|c|c|c|c|c|c|c|c|c|}
\hline & \multicolumn{2}{|c|}{$\begin{array}{c}\text { Baixa } \\
62 \\
\text { municípios }\end{array}$} & \multicolumn{2}{|c|}{$\begin{array}{c}\text { Média } \\
37 \\
\text { municípios }\end{array}$} & \multicolumn{2}{|c|}{$\begin{array}{c}\text { Alta } \\
41 \\
\text { municípios } \\
\end{array}$} & \multicolumn{2}{|c|}{$\begin{array}{c}\text { Muito alta } \\
151 \\
\text { municípios }\end{array}$} & \multicolumn{2}{|c|}{$\begin{array}{c}\text { Brasil } \\
291 \text { municípios }\end{array}$} \\
\hline & Pontos & $\%$ & Pontos & $\%$ & Pontos & $\%$ & Pontos & $\%$ & Pontos & $\%$ \\
\hline \multicolumn{11}{|c|}{ Participação Cívica On-line (PCO) } \\
\hline Fale conosco & 54 & 87,1 & 29 & 78,4 & 34 & 82,9 & 137 & 90,7 & 254 & 87,3 \\
\hline Canais on-line & 21 & 33,9 & 14 & 37,8 & 23 & 56,1 & 98 & 64,9 & 156 & 53,6 \\
\hline Ouvidoria & 33 & 53,2 & 15 & 40,5 & 17 & 41,4 & 90 & 59,6 & 155 & 53,3 \\
\hline e-mails/tels. executivos & 29 & 46,8 & 20 & 54,1 & 27,5 & 67,0 & 112 & 74,2 & 188,5 & 64,8 \\
\hline Total & 137 & 54,4 & 78 & 52,7 & 101,5 & 61,9 & 437 & 72,4 & 753,5 & 64,7 \\
\hline \multicolumn{11}{|c|}{ Controle Social da Gestão (CSG) } \\
\hline Agenda prefeito & 0 & 0,0 & 0 & 0,0 & 0 & 0,0 & 3 & 2,0 & 3 & 1,0 \\
\hline PDDU & 46 & 74,1 & 23 & 62,1 & 30 & 73,2 & 111 & 73,5 & 210 & 72,1 \\
\hline Transparência/e-SIC & 47 & 75,8 & 26,5 & 71,6 & 35,5 & 86,6 & 137,5 & 91,1 & 246,5 & 84,7 \\
\hline Busca & 48 & 77,4 & 34 & 91,9 & 31 & 75,6 & 126 & 83,4 & 239 & 82,1 \\
\hline Total & 141 & 56,8 & 83,5 & 56,4 & 96,5 & 58,8 & 377,5 & 62,5 & 698,5 & 60,0 \\
\hline \multicolumn{11}{|c|}{ Soma dos totais: PCO+CSG } \\
\hline Total & 278 & 56,0 & 161,5 & 54,6 & 198 & 60,4 & 814,5 & 67,4 & 1.452 & 62,4 \\
\hline
\end{tabular}

Fonte: Elaborado pelos autores, com base nos websites das prefeituras.

Convenção: o percentual das ferramentas resulta da relação entre o número de pontos e o número de municípios em cada faixa de TU. O percentual dos totais resulta da relação entre o número de pontos e o produto da multiplicação do número de municípios em cada faixa por quatro, que é o número de ferramentas de cada conjunto PCO e CSG. Os percentuais dos totais da soma dos dois conjuntos $(\mathrm{PCO}+\mathrm{CSG})$ resultam da relação entre o número de pontos e o produto da multiplicação do número de municípios em cada faixa de TU por oito, que é a soma das ferramentas dos dois conjuntos.

Nota-se que sites de municípios de faixas de TU mais elevadas apresentaram maior tendência em disponibilizar e-mails e/ou telefones executivos do que faixas inferiores. Os Canais 
On-line tiveram maior presença em municípios com TU Alta ou Muito Alta. Já o comportamento da ferramenta Ouvidoria foi menos regular, uma vez que sua maior frequência, além de ocorrer na faixa superior da TU (59,6\%), foi seguida pelos municípios com Baixa TU (53,2\%).

A Tabela 1 evidencia ainda que, ao se cruzar as ferramentas de CSG com as faixas de TU, percebe-se que somente os websites de municípios com TU Muito Alta apresentaram a ferramenta Agenda do Prefeito. Vale ressaltar que essa presença representa apenas $2 \%$ dos municípios nessa faixa. Em oposição, as ferramentas mais presentes nessa mesma faixa são Portal da Transparência e e-SIC, com a mesma frequência: 91,1\%.

As ferramentas CSG fizeram-se mais presentes nos websites de municípios com taxa Muito Alta (62,5\%) e menos presentes nos de Média (56,4\%). Os índices de frequência da maioria das ferramentas CSG foram relativamente equilibrados quando analisados sob a luz da variável TU, com exceção da Agenda do Prefeito.

Os dados e o gráfico a seguir permitem inferir que, de modo geral, websites dos municípios brasileiros apresentaram uma distribuição muito próxima entre ferramentas PCO e CSG, mesmo quando agregados por faixas de TU. Enquanto o país apresentou uma frequência de $62,4 \%$ relativa à presença desses dois grupos de ferramentas em conjunto, esse percentual não diferiu acentuadamente das frequências que os municípios obtiveram quando agregados por faixas. O percentual para municípios com faixa de Média TU ficou em $54,6 \%$ e os de Baixa em 56\%. Quando se compara as faixas Alta e Muito Alta, a frequência foi crescente, indo de $60,4 \%$ para $67,4 \%$, esta última superando a do país, que foi de $62,4 \%$.

Note-se que as alturas das barras verde (PCO) e vermelha (CSG) são muito próximas nas faixas iniciais de TU, inclusive no Brasil como um todo, tendo sua maior disparidade face a municípios com taxa Muito Alta (acima de 85\%).

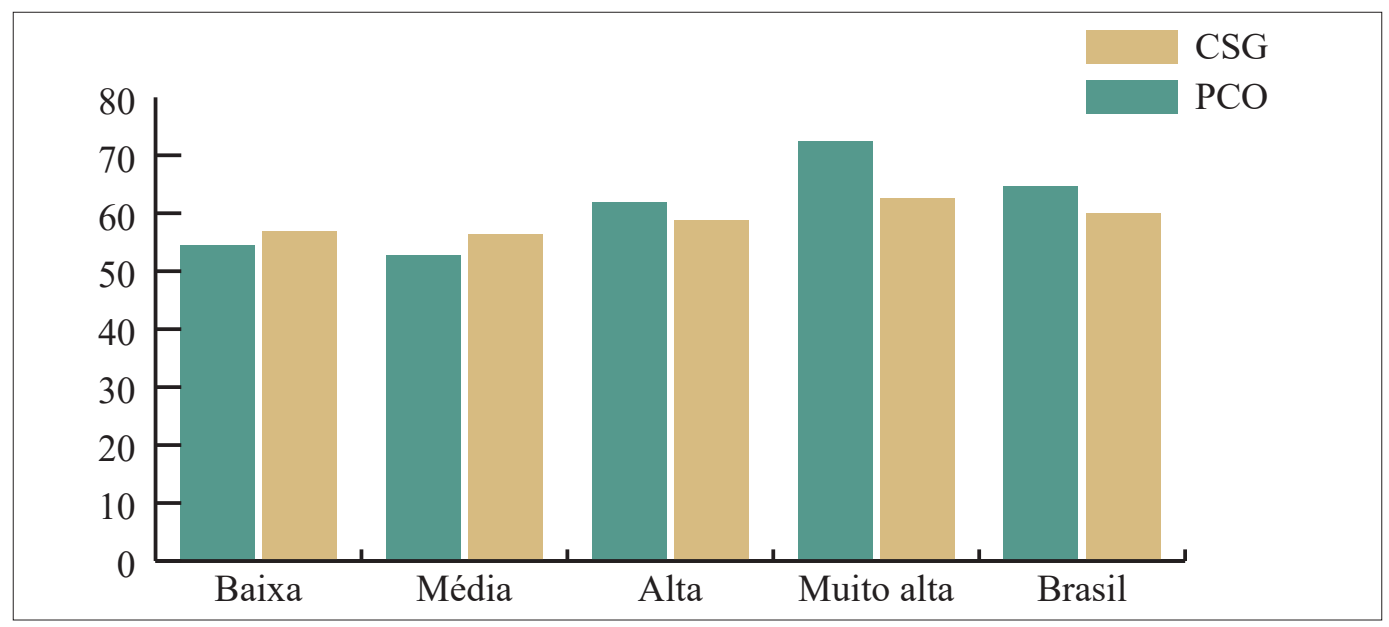

Gráfico 1. Distribuição dos conjuntos de ferramentas PCO e CSG, pelas faixas de TU - Brasil, 2017

Fonte: Elaborado pelos autores, com base nos websites das prefeituras. 
A frequência do grupo de ferramentas PCO superou a de CSG nos websites de municípios com TU mais elevadas. Nos websites dos municípios da faixa Muito Alta, tem-se a maior frequência do grupo PCO $(72,4 \%)$. Nessa faixa, o percentual de CSG foi de $62,5 \%$, superando os das demais, inclusive a que se refere ao Brasil. Infere-se que municípios nas faixas superiores de TU tendem a inovar tecnologicamente quanto às ferramentas disponibilizadas para os cidadãos, enquanto os de faixas mais baixas tendem às mais tradicionais.

Na sequência do trabalho, são analisadas as regiões brasileiras separadamente.

\section{Região Norte}

A Tabela 2 apresenta o cruzamento da presença de ferramentas de website com as faixas de TU dos municípios da Região Norte. Nela, percebe-se que, na faixa Muito Alta, a ferramenta Fale Conosco apresentou $100 \%$ de frequência, sendo majoritária também nas demais faixas, embora com menor percentual. O total de pontos conseguidos pelo conjunto PCO nessa região $(50,7 \%)$ indica que aproximadamente metade dos seus municípios não disponibiliza tais ferramentas aos cidadãos. Curiosamente, a pior situação do conjunto não está nos municípios de TU Baixa, e sim nos de Média, o que nos permite declarar que, pelo menos na Região Norte, os websites das prefeituras não fomentam mais a participação cívica on-line quanto maior é a taxa de urbanização de seus municípios.

Quanto ao CSG, a menor frequência da ferramenta Busca (60\%) ocorreu nos websites de municípios com TU Alta. O item Agenda do Prefeito inexiste nos websites de municípios da região Norte.

Sites de municípios de TU Alta tiveram a maior frequência quanto a ferramentas de CSG (55\%). Seguem-se, respectivamente, as faixas Muito Alta (53,1\%), Baixa (51,9\%), e Média, que obteve a menor frequência (43,8\%).

Quanto à avaliação geral dos websites, por conjunto de ferramentas, os municípios nas faixas Alta ou Muito Alta tiveram melhor desempenho (61,3\% e 61\%, respectivamente) do que os situados na faixa Muito Baixa, com 51,5\%, e na Média, com 39,4\%.

Embora haja evidente equilíbrio entre PCO e CSG, tanto no desempenho global (50,7\% e 50\%, respectivamente), quanto na faixa Baixa (51\% e 51,9\%), é perceptível a disparidade entre os percentuais conseguidos pelos dois conjuntos nas faixas Média, Alta e Muito Alta. 
Tabela 2. Número de pontos conseguidos pelo conjunto de ferramentas PCO e CSG pelas faixas de TU nos websites da Região Norte, 2017

\begin{tabular}{|c|c|c|c|c|c|c|c|c|c|c|}
\hline \multirow[t]{2}{*}{ Ferramentas } & \multicolumn{2}{|c|}{$\begin{array}{c}\text { Baixa } \\
13 \text { municípios }\end{array}$} & \multicolumn{2}{|c|}{$\begin{array}{l}\text { Média } \\
10 \text { municípios }\end{array}$} & \multicolumn{2}{|c|}{$\begin{array}{c}\text { Alta } \\
5 \text { municípios }\end{array}$} & \multicolumn{2}{|c|}{$\begin{array}{c}\text { Muito alta } \\
4 \text { municípios }\end{array}$} & \multicolumn{2}{|c|}{$\begin{array}{c}\text { Total } \\
32 \text { municípios }\end{array}$} \\
\hline & Pontos & $\%$ & Pontos & $\%$ & Pontos & $\%$ & Pontos & $\%$ & Pontos & $\%$ \\
\hline \multicolumn{11}{|c|}{ Participação Cívica On-line (PCO) } \\
\hline Fale conosco & 11 & 84,6 & 7 & 70,0 & 4 & 80,0 & 4 & 100,0 & 26 & 81,2 \\
\hline Canais on-line & 4 & 30,8 & 3 & 30,0 & 2 & 40,0 & 2 & 50,0 & 11 & 34,3 \\
\hline Ouvidoria & 5 & 38,5 & 1 & 10,0 & 4 & 80,0 & 2 & 50,0 & 12 & 37,5 \\
\hline $\begin{array}{c}\text { e-mails/tels. } \\
\text { executivos }\end{array}$ & 6,5 & 50,0 & 3 & 30,0 & 3,5 & 70,0 & 3 & 75,0 & 16 & 46,8 \\
\hline Total & 26,5 & 51,0 & 14 & 35,0 & 13,5 & 67,5 & 11 & 68,8 & 65 & 50,7 \\
\hline \multicolumn{11}{|c|}{ Controle Social da Gestão (CSG) } \\
\hline Agenda prefeito & 0 & 0,0 & 0 & 0,0 & 0 & 0,0 & 0 & 0,0 & 0 & 0,0 \\
\hline PDDU & 9 & 69,2 & 5 & 50,0 & 4 & 80,0 & 2 & 50,0 & 20 & 62,5 \\
\hline $\begin{array}{c}\text { Transparência/ } \\
\text { e-SIC }\end{array}$ & 8 & 61,5 & 4,5 & 45,0 & 4 & 80,0 & 2,5 & 62,5 & 19 & 59,3 \\
\hline Busca & 10 & 76,9 & 8 & 80,0 & 3 & 60,0 & 4 & 100,0 & 25 & 78,1 \\
\hline Total & 27 & 51,9 & 17,5 & 43,8 & 11 & 55,0 & 8,5 & 53,1 & 64 & 50,0 \\
\hline \multicolumn{11}{|c|}{ Soma dos totais: PCO+CSG } \\
\hline Total & 53,5 & 51,5 & 31,5 & 39,4 & 24,5 & 61,3 & 19,5 & 61,0 & 129 & 50,4 \\
\hline
\end{tabular}

Fonte: Elaborado pelos autores, com base nos websites das prefeituras.

Convenção: Vide Tabela 1.

\section{Região Nordeste}

Tal como na Região Norte, no Nordeste os websites de municípios situados nas faixas superiores de TU tiveram maior presença de ferramentas PCO, sendo de 70,3\% para a faixa Alta e de 76,7\% na faixa Muito Alta, conforme Tabela 3. Nas faixas inferiores, os percentuais ficaram em 53,1\% (TU Baixa) e 56,2\% (TU Média).

Quanto às ferramentas de CSG, Busca destaca-se com 85,8\%. Vem seguida por Portal da Transparência/e-SIC, com frequência de 82\%. Agenda do Prefeito tem a mais baixa frequência dentre as demais ferramentas: 1\%. A presença do PDDU ficou com $68,4 \%$, ocupando o penúltimo lugar. Nota-se também que a maior frequência para o conjunto CSG está na faixa de TU Média, com 62,5\%.

Quando observados os grupos de ferramentas segundo as faixas de TU, não se identifica uma predominância constante de nenhum dos dois conjuntos de ferramentas sobre o outro: PCO está melhor nas duas faixas superiores, perfazendo $70,3 \%$ contra $57,8 \%$ do 
CSG na terceira faixa; e 76,7\% contra 59,6\% na Muito Alta. CSG se apresenta melhor das duas faixas inferiores: $58 \%$ contra 53,1\% de PCO na Baixa; e 62,5\% contra 56,2\% na faixa de Média. Assim, a frequência de ferramentas nos websites, quando comparados os dois conjuntos, não se relaciona em termos causais, linear e progressivamente, com a TU, já que, em um deles, a melhor situação é nas faixas mais baixas e, no outro, é nas mais altas.

Há uma relação causal ascendente nítida entre a frequência das ferramentas PCO nos websites dos municípios nordestinos e as faixas de TU. Essa é uma situação ímpar exclusivamente das ferramentas de PCO nesta região. O mesmo fenômeno se observa na soma dos dois conjuntos de ferramentas por faixas de TU: 55,6\%, 59,4\%, 64, $1 \%$ e $68,1 \%$.

Tabela 3. Número de pontos conseguidos pelos websites quanto aos conjuntos de ferramentas PCO e CSG pelas faixas de TU nos websites da região Nordeste, 2017

\begin{tabular}{|c|c|c|c|c|c|c|c|c|c|c|}
\hline \multirow[t]{2}{*}{ Ferramentas } & \multicolumn{2}{|c|}{$\begin{array}{c}\text { Baixa } \\
36 \text { municípios }\end{array}$} & \multicolumn{2}{|c|}{$\begin{array}{c}\text { Média } \\
18 \text { municípios }\end{array}$} & \multicolumn{2}{|c|}{$\begin{array}{c}\text { Alta } \\
8 \text { municípios }\end{array}$} & \multicolumn{2}{|c|}{$\begin{array}{l}\text { Muito alta } \\
30 \text { municípios }\end{array}$} & \multicolumn{2}{|c|}{$\begin{array}{c}\text { Total } \\
92 \text { municípios }\end{array}$} \\
\hline & Pontos & $\%$ & Pontos & $\%$ & Pontos & $\%$ & Pontos & $\%$ & Pontos & $\%$ \\
\hline \multicolumn{11}{|c|}{ Participação Cívica On-line (PCO) } \\
\hline Fale conosco & 30 & 83,3 & 14 & 77,8 & 8 & 100 & 26 & 86,7 & 78 & 84,7 \\
\hline Canais on-line & 12 & 33,3 & 8 & 44,4 & 6 & 75,0 & 20 & 66,7 & 46 & 50,0 \\
\hline Ouvidoria & 21 & 58,3 & 10 & 55,6 & 5 & 62,5 & 22 & 73,3 & 58 & 63,0 \\
\hline $\begin{array}{l}\text { e-mails/tels. } \\
\text { executivos }\end{array}$ & 13,5 & 37,5 & 8,5 & 47,2 & 3,5 & 43,8 & 24 & 80,0 & 49,5 & 53,8 \\
\hline Total & 76,5 & 53,1 & 40,5 & 56,2 & 22,5 & 70,3 & 92 & 76,7 & 235 & 63,8 \\
\hline \multicolumn{11}{|c|}{ Controle Social da Gestão (CSG) } \\
\hline $\begin{array}{l}\text { Agenda } \\
\text { prefeito }\end{array}$ & 0 & 0 & 0 & 0 & 0 & 0 & 1 & 3,3 & 1 & 1,0 \\
\hline PDDU & 28 & 84,8 & 12 & 70,6 & 5 & 62,5 & 18 & 64,3 & 63 & 68,4 \\
\hline $\begin{array}{c}\text { Transparência/ } \\
\text { e-SIC }\end{array}$ & 28,5 & 79,2 & 15 & 83,3 & 6,5 & 81,2 & 25,5 & 85,0 & 75,5 & 82,0 \\
\hline Busca & 27 & 75,0 & 18 & 100,0 & 7 & 87,5 & 27 & 90,0 & 79 & 85,8 \\
\hline Total & 83,5 & 58,0 & 45 & 62,5 & 18,5 & 57,8 & 71,5 & 59,6 & 218,5 & 59,3 \\
\hline \multicolumn{11}{|c|}{ Soma dos totais: PCO+CSG } \\
\hline Total & 160,0 & 55,6 & 85,5 & 59,4 & 41,0 & 64,1 & 163,5 & 68,1 & 450 & 61,1 \\
\hline
\end{tabular}

Fonte: Elaborado pelos autores, com base nos websites das prefeituras.

Convenção: Vide Tabela 1.

\section{Região Sudeste}

Avaliando a região Sudeste quanto ao grupo de ferramentas PCO (Tabela 4), observa-se que, mais uma vez, Fale Conosco ocupa o primeiro lugar, com 91,9\%, seguida por e-mails e/ou telefones executivos, com $71,7 \%$ de frequência. Nas faixas inferiores de TU, 
temos uma variação acentuada quanto à presença das ferramentas PCO. Nos municípios com TU Baixa, enquanto Fale Conosco e e-mails e/ou telefones executivos receberam respectivamente $100 \%$ e $83,3 \%$, Canais On-line e Ouvidoria tiveram uma presença de 33,3\% cada. Na faixa imediatamente superior (Média), chama a atenção a ausência de Ouvidoria nos websites avaliados. É surpreendente também a pequena presença de Ouvidoria nos municípios com TU Alta (20\%). Já naqueles da faixa Muito Alta a presença das quatro ferramentas PCO é mais equitativa, novamente com destaque para Fale Conosco.

Tabela 4. Número de pontos conseguidos pelos websites quanto aos conjuntos de ferramentas PCO e CSG pelas faixas de TU nos websites da Região Sudeste, 2017

\begin{tabular}{|c|c|c|c|c|c|c|c|c|c|c|}
\hline \multirow[t]{2}{*}{ Ferramentas } & \multicolumn{2}{|c|}{$\begin{array}{c}\text { Baixa } \\
6 \text { municípios }\end{array}$} & \multicolumn{2}{|c|}{$\begin{array}{c}\text { Média } \\
4 \text { municípios } \\
\end{array}$} & \multicolumn{2}{|c|}{$\begin{array}{c}\text { Alta } \\
10 \text { municípios }\end{array}$} & \multicolumn{2}{|c|}{$\begin{array}{c}\text { Muito alta } \\
79 \text { municípios }\end{array}$} & \multicolumn{2}{|c|}{$\begin{array}{c}\text { Total } \\
99 \text { municípios } \\
\end{array}$} \\
\hline & Pontos & $\%$ & Pontos & $\%$ & Pontos & $\%$ & Pontos & $\%$ & Pontos & $\%$ \\
\hline \multicolumn{11}{|c|}{ Participação Cívica On-line (PCO) } \\
\hline Fale conosco & 6 & 100,0 & 4 & 100,0 & 8 & 80,0 & 73 & 92,4 & 91 & 91,9 \\
\hline Canais on-line & 2 & 33,3 & 2 & 50,0 & 7 & 70,0 & 51 & 64,6 & 62 & 62,6 \\
\hline Ouvidoria & 2 & 33,3 & 0 & 0 & 2 & 20,0 & 39 & 49,4 & 43 & 43,4 \\
\hline $\begin{array}{l}\text { e-mails/tels. } \\
\text { executivos }\end{array}$ & 5 & 83,3 & 3,5 & 87,5 & 7 & 70,0 & 55,5 & 70,3 & 71 & 71,7 \\
\hline Total & 15 & 62,5 & 9,5 & 59,4 & 24 & 60,0 & 218,5 & 69,2 & 267 & 67,4 \\
\hline \multicolumn{11}{|c|}{ Controle Social da Gestão (CSG) } \\
\hline $\begin{array}{l}\text { Agenda } \\
\text { prefeito }\end{array}$ & 0 & 0,0 & 0 & 0,0 & 0 & 0,0 & 1 & 1,3 & 1 & 1,1 \\
\hline PDDU & 3 & 60,0 & 2 & 50,0 & 6 & 60,0 & 58 & 74,4 & 69 & 69,6 \\
\hline $\begin{array}{c}\text { Transparência/ } \\
\text { e-SIC }\end{array}$ & 5 & 83,3 & 2,5 & 62,5 & 9,5 & 95,0 & 71,5 & 90,5 & 88,5 & 89,3 \\
\hline Busca & 5 & 83,3 & 3 & 75,0 & 10 & 100 & 63 & 79,7 & 81 & 81,8 \\
\hline Total & 13 & 54,2 & 7,5 & 46,9 & 25,5 & 63,8 & 193,5 & 61,2 & 239,5 & 60,4 \\
\hline \multicolumn{11}{|c|}{ Soma dos totais: PCO+CSG } \\
\hline Total & 28 & 58,3 & 17 & 53,1 & 49,5 & 61,9 & 412 & 65,2 & 506,5 & 63,9 \\
\hline
\end{tabular}

Fonte: Elaborado pelos autores, com base nos websites das prefeituras. Convenção: Vide Tabela 1.

Quanto ao CSG, a faixa com maior presença dessas ferramentas é a Alta: 63,8\%. A faixa Muito Alta conquistou o segundo melhor desempenho $(61,2 \%)$. Nas faixas inferiores, temos, respectivamente, Baixa com 54,2\% e Média com 46,9\%.

$\mathrm{Na}$ soma dos totais a faixa Muito Alta obteve melhor desempenho: $65,2 \%$, seguida pela Alta (61,9\%). Para os municípios com TU Baixa, o desempenho global foi de $58,3 \%$, enquanto os websites dos municípios integrantes da faixa Média ficaram com o 
pior desempenho: 53,1\%. Ressalta-se a constante raridade da Agenda do Prefeito $(1,1 \%)$, que só pontuou em um município da faixa Muito Alta.

\section{Região Sul}

Da mesma forma que em todas as regiões, no Sul (Tabela 5), a ferramenta Fale Conosco teve a maior frequência: $83,3 \%$. Contudo ela apresenta menor prevalência nas duas faixas intermediárias de TU do que nas extremas: Baixa (100\%) e Muito Alta (88,9\%). Nesta região, todos os municípios com TU Média disponibilizam e-mails e/ou telefones executivos em seus websites, bem como Ouvidoria. Também nesta faixa está a menor frequência para Canais On-line - 33,3\% - demonstrando que, mesmo em uma região rica como a Sul, websites apresentam-se defasados em termos de comunicação online.

Tabela 5. Número de pontos conseguidos pelos websites quanto aos conjuntos de ferramentas PCO e CSG pelas faixas de TU nos websites da Região Sul, 2017

\begin{tabular}{|c|c|c|c|c|c|c|c|c|c|c|}
\hline \multirow[t]{2}{*}{ Ferramentas } & \multicolumn{2}{|c|}{$\begin{array}{c}\text { Baixa } \\
5 \text { municípios }\end{array}$} & \multicolumn{2}{|c|}{$\begin{array}{l}\text { Média } \\
3 \text { municípios }\end{array}$} & \multicolumn{2}{|c|}{$\begin{array}{c}\text { Alta } \\
13 \text { municípios }\end{array}$} & \multicolumn{2}{|c|}{$\begin{array}{l}\text { Muito alta } \\
27 \text { municípios }\end{array}$} & \multicolumn{2}{|c|}{$\begin{array}{c}\text { Total } \\
48 \text { municípios }\end{array}$} \\
\hline & Pontos & $\%$ & Pontos & $\%$ & Pontos & $\%$ & Pontos & $\%$ & Pontos & $\%$ \\
\hline \multicolumn{11}{|c|}{ Participação Cívica On-line (PCO) } \\
\hline Fale conosco & 5 & 100,0 & 2 & 66,7 & 9 & 69,2 & 24 & 88,9 & 40 & 83,3 \\
\hline Canais on-line & 2 & 40,0 & 1 & 33,3 & 5 & 38,5 & 18 & 66,7 & 26 & 54,1 \\
\hline Ouvidoria & 4 & 80,0 & 3 & 100,0 & 3 & 23,1 & 18 & 66,7 & 28 & 58,3 \\
\hline $\begin{array}{l}\text { e-mails/tels. } \\
\text { executivos }\end{array}$ & 3 & 60,0 & 3 & 100,0 & 10 & 76,9 & 20,5 & 75,9 & 36,5 & 76,0 \\
\hline Total & 14 & 70,0 & 9 & 75,0 & 27 & 51,9 & 80,5 & 74,5 & 130,5 & 67,9 \\
\hline \multicolumn{11}{|c|}{ Controle Social da Gestão (CSG) } \\
\hline $\begin{array}{l}\text { Agenda } \\
\text { prefeito }\end{array}$ & 0 & 0,0 & 0 & 0,0 & 0 & 0,0 & 0 & 0,0 & 0 & 0,0 \\
\hline PDDU & 5 & 100 & 3 & 100 & 10 & 76,9 & 24 & 92,3 & 42 & 87,5 \\
\hline $\begin{array}{c}\text { Transparência/ } \\
\text { e-SIC }\end{array}$ & 4,5 & 90,0 & 3 & 100 & 12 & 92,3 & 27 & 100 & 46,5 & 96,8 \\
\hline Busca & 4 & 80,0 & 3 & 100 & 8 & 61,5 & 24 & 88,9 & 39 & 81,2 \\
\hline Total & 13,5 & 67,5 & 9 & 75,0 & 30 & 57,7 & 75 & 69,4 & 127,5 & 66,4 \\
\hline \multicolumn{11}{|c|}{ Soma dos totais: PCO+CSG } \\
\hline Total & 27,5 & 68,75 & 18 & 75,0 & 57 & 54,8 & 155,5 & 72,0 & 258 & 67,1 \\
\hline
\end{tabular}

Fonte: Elaborado pelos autores, com base nos websites das prefeituras. Convenção: Vide Tabela 1.

Também aqui chama a atenção a total ausência da Agenda do Prefeito, em contraste com a presença relevante das outras ferramentas em todas as faixas de TU. 
Tanto em PCO, quanto em CSG e, consequentemente, na soma dos totais, os percentuais não seguem uma ordem crescente ou decrescente de acordo com as faixas de TU, ziguezagueando entre elas. Os dados confirmam, portanto, a ausência de relação causal entre a TU e a frequência de ferramentas, nessa região.

\section{Região Centro-Oeste}

Nesta região (Tabela 6), o total de pontos conseguido pelo conjunto PCO (74,3\%) é relativamente alto, indicando um bom fomento à participação on-line dos cidadãos. Excluída a ferramenta líder Fale Conosco, Ouvidoria e e-mails e/ou telefones executivos têm na faixa Muito Alta o mesmo percentual $(81,8 \%)$, superior a Canais On-line $(63,6 \%)$. $\mathrm{Na}$ faixa de TU Média, e-mails e/ou telefones executivos tem $100 \%$ de frequência, o mesmo percentual de Fale Conosco. No total PCO, as faixas Baixa e Média obtiveram a mesma pontuação (62,5\%), abaixo da pontuação obtida pelos municípios com TU Alta ou Muito Alta (respectivamente, 72,5\% e 79,5\%).

Tabela 6. Número de pontos conseguidos pelos websites quanto aos conjuntos de ferramentas PCO e CSG pelas faixas de TU nos websites da Região Centro-Oeste, 2017

\begin{tabular}{|c|c|c|c|c|c|c|c|c|c|c|}
\hline \multirow[t]{2}{*}{ Ferramentas } & \multicolumn{2}{|c|}{$\begin{array}{c}\text { Baixa } \\
2 \text { municípios }\end{array}$} & \multicolumn{2}{|c|}{$\begin{array}{c}\text { Média } \\
2 \text { municípios }\end{array}$} & \multicolumn{2}{|c|}{$\begin{array}{c}\text { Alta } \\
5 \text { municípios } \\
\end{array}$} & \multicolumn{2}{|c|}{$\begin{array}{c}\text { Muito alta } \\
11 \text { municípios }\end{array}$} & \multicolumn{2}{|c|}{$\begin{array}{c}\text { Total } \\
20 \text { municípios }\end{array}$} \\
\hline & Pontos & $\%$ & Pontos & $\%$ & Pontos & $\%$ & Pontos & $\%$ & Pontos & $\%$ \\
\hline \multicolumn{11}{|c|}{ Participação Cívica On-line (PCO) } \\
\hline Fale conosco & 2 & 100 & 2 & 100 & 5 & 100 & 10 & 90,9 & 19 & 95,0 \\
\hline Canais on-line & 1 & 50,0 & 0 & 0,0 & 3 & 60,0 & 7 & 63,6 & 11 & 55,0 \\
\hline Ouvidoria & 1 & 50,0 & 1 & 50,0 & 3 & 60,0 & 9 & 81,8 & 14 & 70,0 \\
\hline $\begin{array}{l}\text { e-mails/tels. } \\
\text { executivos }\end{array}$ & 1 & 50,0 & 2 & 100 & 3,5 & 70,0 & 9 & 81,8 & 15,5 & 77,5 \\
\hline Total & 5 & 62,5 & 5 & 62,5 & 14,5 & 72,5 & 35 & 79,5 & 59,5 & 74,3 \\
\hline \multicolumn{11}{|c|}{ Controle Social da Gestão (CSG) } \\
\hline $\begin{array}{l}\text { Agenda } \\
\text { prefeito }\end{array}$ & 0 & 0,0 & 0 & 0,0 & 0 & 0,0 & 1 & 9,1 & 1 & 1,0 \\
\hline PDDU & 1 & 50,0 & 1 & 50,0 & 5 & 100 & 9 & 81,8 & 16 & 80,0 \\
\hline $\begin{array}{c}\text { Transparência/ } \\
e \text {-SIC }\end{array}$ & 1 & 50,0 & 1,5 & 75,0 & 3,5 & 70,0 & 11 & 100 & 17 & 85,0 \\
\hline Busca & 2 & 100 & 2 & 100 & 3 & 60,0 & 8 & 72,7 & 15 & 75,0 \\
\hline Total & 4 & 50,0 & 4,5 & 56,2 & 11,5 & 57,5 & 29 & 65,9 & 49 & 61,2 \\
\hline \multicolumn{11}{|c|}{ Soma dos totais: PCO+CSG } \\
\hline Total & 9 & 56,3 & 9,5 & 59,4 & 26 & 65,0 & 64 & 72,7 & 108,5 & 67,8 \\
\hline
\end{tabular}

Fonte: Elaborado pelos autores, com base nos websites das prefeituras. Convenção: Vide Tabela 1. 
No conjunto de ferramentas relativas ao CSG, os desempenhos globais acompanham o crescimento das faixas de TU: $50 \%, 56,2 \%, 57,5 \%$ e $65,9 \%$, respectivamente. Esse comportamento não se repete em qualquer outra região.

Relação ascendente análoga é observada para a soma dos totais: PCO+CSG. A primeira faixa tem $56,3 \%$ de presença; a segunda, $59,4 \%$; a terceira, $65,0 \%$; e a faixa mais alta salta para 72,7\%. Esse fenômeno se repete apenas na Região Nordeste (Tabela 3).

\section{Análise}

No cruzamento dos dados com as faixas da TU dos municípios, considerado o país como um todo, verifica-se que entre as ferramentas de PCO, Fale Conosco é a mais frequente em todas as faixas (Tabela 1). Consideradas as regiões, ela repete a performance nos totais de todas elas (Tabelas 2 a 6). As ferramentas Canais On-line e Ouvidoria dividem as menores frequências, quer se considere o Brasil como um todo, quer se considere as faixas isoladamente, com exceção apenas do Nordeste, em que Ouvidoria supera e-mails e/ou telefones executivos no total da região.

No conjunto CSG, Agenda do Prefeito é, de longe, a menos frequente, atingindo apenas $1 \%$ no total e somente tem presença na faixa superior de TU. Consideradas as regiões per se, as mais frequentes são Transparência/e-SIC nas regiões Sudeste, Sul e Centro-Oeste, enquanto Busca é mais frequente nas regiões Norte e Nordeste.

A ferramenta Transparência/e-SIC é, na verdade, um conjunto de duas sub-ferramentas, obrigatórias por lei, cabendo à primeira, disponibilizar informações gerenciais, como dados orçamentários, licitações e receitas/despesas em geral; a segunda é um canal que deve estar disponível para o cidadão obter outras informações não disponibilizadas em qualquer parte do website. A disponibilização das duas não é, portanto, voluntária, de iniciativa própria da prefeitura, mas obrigação legal. Ainda assim, sua frequência continua baixa no Norte do país. Nas demais regiões, contudo, a lei é cumprida por um alto percentual de websites.

Há que ressaltar a existência, no Nordeste, de relações causais lineares entre as ferramentas de PCO e a TU, assim como na soma dos dois conjuntos de ferramentas (PCO e CSG). Fenômeno similar se verifica na Região Centro-Oeste; neste caso, ocorre tanto no que se refere a ferramentas de CSG, quanto na soma dos dois conjuntos de ferramentas. Em ambos os casos, a frequência das ferramentas aumenta linearmente na medida em que aumenta a TU. Nas demais regiões, não há relação linear de nenhum tipo.

Embora no Sul a pontuação alcançada seja superior à observada no Nordeste $(75 \%$ contra $62,5 \%$ ), esta última região possui apenas $41,3 \%$ dos municípios da amostra nas 
duas faixas superiores de TU, enquanto na primeira, essas faixas constituem $83,3 \%$ do total. Dado que o Sul tem um maior número de municípios nessas duas faixas, a tendência seria a de que o primeiro lugar em frequência de ferramentas na região fosse ocupado por uma das duas faixas superiores, o que não ocorreu: o primeiro lugar está com a faixa Média, seguida da Muito Alta e, depois, da Baixa, encerrando com a Alta.

Em relação ao desempenho global dos conjuntos de ferramentas PCO e CSG por faixa de TU, verifica-se que ambos estão mais presentes nas faixas mais altas, ainda que, excepcionalmente no Sul, a faixa Média lidere e a faixa Alta esteja em último lugar.

Adiante são calculados os valores do coeficiente de correlação entre ferramentas websites e TU, onde se observa que os maiores graus de associação entre as ferramentas de PCO e as faixas de TU ocorrem exatamente nas regiões Nordeste e Centro-Oeste.

\section{Análise de correlações}

Foi calculada a correlação ${ }^{8}$ entre as variáveis TU e ferramentas de websites, cujo valor foi de 0,29 , indicando uma fraca associação positiva entre elas. Separadamente, por cada ferramenta de website, encontrou-se uma associação de 0,32 entre TU e PCO, e uma associação mais baixa ainda $(0,14)$ entre TU e CSG. Foi adotada a convenção da tabela a seguir para interpretar os valores das correlações encontrados.

Tabela 7. Referência para interpretar o valor da correlação

\begin{tabular}{c|c} 
Valores de $\square(+$ ou -$)$ & Interpretação \\
0,00 a 0,19 & Correlação muito fraca \\
\hline 0,20 a 0,39 & Correlação fraca \\
\hline 0,40 a 0,69 & Correlação moderada \\
\hline 0,70 a 0,89 & Correlação forte \\
\hline 0,90 a 1,00 & Correlação muito forte \\
\hline
\end{tabular}

Fonte: Elaborado pelos autores.

Investigando essa associação por regiões, a Tabela 8 mostra que, tal como acontece para o Brasil, as associações por região são sempre no sentido positivo entre faixas de TU e o total das ferramentas. Já nas avaliações isoladas por grupo de ferramentas, percebe-se que o grupo CSG tem as associações mais fracas nas regiões Norte e Nordeste do que nas demais. Além disso, o valor chega a ser negativo na região Norte.

8 Foi adotado o coeficiente de correlação de Spearman, devido à característica ordinal das variáveis.

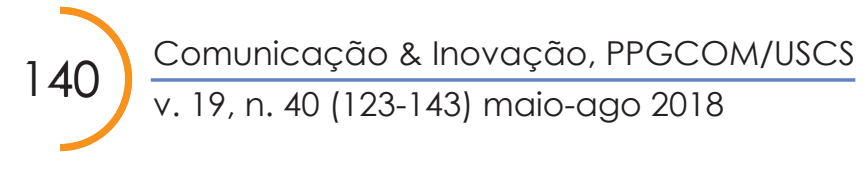


Tabela 8. Valor da correlação entre TU e ferramentas de websites, por região

\begin{tabular}{c|c|c|c|c|c} 
Ferramentas & Norte & Nordeste & Sudeste & Sul & Centro-oeste \\
\hline PCO & 0,24 & 0,39 & 0,15 & 0,22 & 0,39 \\
\hline CSG & $-0,02$ & 0,01 & 0,13 & 0,16 & 0,28 \\
\hline Total & 0,18 & 0,30 & 0,17 & 0,22 & 0,35 \\
\hline
\end{tabular}

Fonte: Elaborado pelos autores.

Nota-se que os valores mais altos de correlação da TU é com PCO para as regiões Nordeste e Centro-Oeste. Isso corrobora as análises feitas nas tabelas 3 e 6, referentes a essas regiões específicas. Por outro lado, ainda não pode ser classificada como uma correlação moderada.

De maneira global, a taxa de urbanização está fracamente ou muito fracamente relacionada com as ferramentas de participação (Fale Conosco, Canais On-line, Ouvidoria e e-mails e/ou telefones executivos) e também com as de controle social da gestão (Agenda do Prefeito, PDDU, Portal da Transparência/e-SIC e Busca) presentes nos websites.

\section{Conclusão}

Buscou-se neste trabalho saber se os municípios brasileiros usam as TIC para promover transparência da gestão e incrementar o exercício da cidadania. Para isto foram analisados os websites das prefeituras, visando verificar se são utilizados para promover maior proximidade entre a gestão e os seus cidadãos, por meio de prática efetiva de e-Governo.

Hipoteticamente, esperava-se que os websites das prefeituras contivessem boa oferta de ferramentas digitais, fomentadoras de transparência e de participação cívica. Eles, na verdade, devem expor o pensamento do governo municipal sobre seu conteúdo, em termos de informação e ferramentas de participação. Considerando o que revela a pesquisa, vê-se que, embora disponibilizem ferramentas de comunicação com os cidadãos - como é o caso da ferramenta Fale Conosco -, não disponibilizam a Agenda do Prefeito, o recurso mais ausente dentre todos os pesquisados. Em duas das cinco regiões, ela simplesmente é inexistente, e nas demais aparece em apenas um website de cada região, representando $1 \%$ dos 291 municípios brasileiros pesquisados. O que faz, quem recebe, quem visita, para onde viaja, qual a dinâmica do dia a dia do chefe do executivo municipal são informações negadas ao público.

A ser realçado, também, o fato de serem pouco disponibilizadas nos websites ferramentas mais contemporâneas de comunicação como canais online do tipo Wikis, Twitter, YouTube, Instagram ou Facebook, por exemplo. Essas redes sociais digitais permitem 
compartilhamento de ideias e imagens, o que certamente impulsiona a interação prefeitura-munícipes, particularmente com o público jovem.

Municípios com maior taxa de urbanização têm melhores websites, em termos de oferta de ferramentas? Em princípio sim: os dados da pesquisa mostram que as ferramentas de participação (Fale Conosco, Canais On-line, Ouvidoria e e-mails e/ou telefones executivos) e as de controle social da gestão (Agenda do Prefeito, Plano Diretor, Portal da Transparência/e-SIC e Busca) estão mais presentes nos websites dos municípios com maior taxa de urbanização.

Dois fenômenos devem ser evidenciados: no Centro-Oeste, há relações causais plenas de TU com Participação Cívica On-line, Controle Social da Gestão e com a soma desses dois conjuntos de ferramentas; já no Nordeste esse fenômeno se verifica com o primeiro e com a soma das duas ferramentas, não ocorrendo com CSG. Em ambas as regiões, a frequência das ferramentas aumenta linearmente na medida em que aumenta a taxa de urbanização. Nas demais não há relação linear de nenhum tipo, o que indica atipicidade do Nordeste e do Centro-Oeste.

A análise estatística de correlações, por seu turno, que trata de associações globais por grupo de ferramentas, confirma as relações causais identificadas, inclusive no que se refere à existência de relações de efeito ascendente e descendente. Esta análise demonstra também que é fraca a correlação entre as ferramentas de website e a TU.

De maneira geral, portanto, os dados mostram que os websites das prefeituras padecem da ausência de ferramentas que estimulem a interação entre povo e governo, da mesma forma que não primam pela oferta plena de possibilidades para a prática democrática. É evidente o pouco esforço no sentido de fomentar o uso das TIC para o exercício da cidadania, mesmo em municípios com taxas de urbanização mais elevadas.

Por fim, parece ainda necessário estimular o poder público dos municípios a compreender que websites não devem ser considerados instrumentos de propaganda de governo ou vitrines formais de gestão. Devem ser locais de interação entre o poder público e os cidadãos, por meio dos quais a municipalidade seja enxertada, permanentemente, de sugestões, críticas, proposições, requerimentos, apoios e apupos, expressões legítimas de relevante participação cívica.

\section{Referências}

BERG, L.; WINDEN, W.. Should cities help their citizens to adopt ICTs? On ICT-adoption policies in European cities. Environment and Planning C: Politics and Space, Thousand Oaks, v. 20, n. 2, p. 263-279, abr. 2002.

$142 \frac{\text { Comunicação \& Inovação, PPGCOM/USCS }}{\text { v. 19, n. } 40 \text { (123-143) maio-ago } 2018}$ 
BOLFARINE, H.; BUSSAB, W. O. Elementos de amostragem. ABE - Projeto Fisher. São Paulo: Edgar Blücher, 2005.

BRASIL. Constituição da República Federativa do Brasil, de 5 de outubro de 1988. Diário Oficial da União, Poder Legislativo, Brasília, DF, 5 out. 1988. Seção 1, p. 1. Disponível em: <https://bit. ly/1bIJ9XW>. Acesso em: 29 maio 2018.

Lei Complementar n. 101, de 4 de maio de 2000. Lei de Responsabilidade Fiscal. Estabelece normas de finanças públicas voltadas para a responsabilidade na gestão fiscal e dá outras providências. Diário Oficial da União, Poder Legislativo, Brasília, DF, 5 maio 2000. Seção 1, p. 1. Disponível em: <https://bit.ly/2xokexz>. Acesso em: 29 maio 2018.

Lei Complementar n. 131, de 27 de maio de 2009. Lei da Transparência. Diário Oficial da União, Poder Legislativo, Brasília, DF, 28 maio 2009. Seção 1, p. 2. Disponível em: <https://bit.ly/2IZlhFe>. Acesso em: 29 maio 2018.

Lei n. 12.527, de 18 de novembro de 2011. Lei de Acesso à Informação. Diário Oficial da União, Poder Legislativo, Brasília, DF, 18 nov. 2011. Seção 1, p. 1. Disponível em: <https://bit.ly/2IUzU$\mathrm{xV}>$. Acesso em: 29 maio 2018.

CASTELLS, M. The informational city. Oxford: Blackwell Publishers Inc., 2002.

INSTITUTO BRASILEIRO DE GEOGRAFIA E ESTATÍsTICA. Censo 2010. Brasília: IBGE, 2010. Disponível em: https://bit.ly/2sPwMce. Acesso em: 30/09/2016.

Estimativas populacionais para os municípios e para as Unidades da Federação brasileiros em 01.07.2016. Brasília: IBGE, 2016. Disponível em: https://bit.ly/2wKPgdV. Acesso em: 30/09/2016.

SORJ, B.Brasil@povo.com: a luta contra a desigualdade na sociedade da informação. Rio de Janeiro: Jorge Zahar, 2003.

TEIXEIRA, A. O uso das novas tecnologias de informação e comunicação (TIC) e a transparência na gestão pública municipal no Ceará. Fortaleza: Fundação Konrad Adenauer, 2004.

UHLIR, P. F. Diretrizes políticas para o desenvolvimento e a promoção da informação governamental de domínio público. Brasília, DF: Unesco, 2006. Disponível em: <https://bit.ly/2L3nPTu>. Acesso em: 29 maio 2006.

WHEELER, J. O.; AOYAMA, Y.; WARF, B. Cities in the telecommunications age. New York: Routledge, 2000. 